\title{
Structural failure of old reinforced concrete river wharf
}

\author{
Grzegorz Dmochowski ${ }^{1}$, Piotr Berkowski ${ }^{2, *}$ \\ ${ }^{1}$ Wroclaw University of Science and Technology, Faculty of Civil Engineering, Wyspianskiego Blvd., 27, Wroclaw, Poland \\ ${ }^{2}$ Wroclaw University of Science and Technology, Faculty of Civil Engineering, Wyspianskiego Blvd., 27, Wroclaw, Poland
}

\begin{abstract}
According to the archival documentation the river harbour wharf was constructed around 1912. The quay was divided into 6 separated segments with a length of $32.0 \mathrm{~m}$ each. The structure of the wharf consists of the reinforced concrete frames situated perpendicularly to the riverbed. At ground level, the frames are connected by a reinforced concrete deck and longitudinal beams, located along the side of the river and the quay. The frames are also connected along the riverside by the concrete cap situated at the top of the retaining wall made of prefabricated panels and embedded in the bottom of the river. That wall constitutes a direct strengthening and protection of the embankment against the influence of the flowing river water. Basing on the performed inventory inspections, material examination, structural calculations and hydro-geotechnical analyses, the main reasons for the failure of the reinforced concrete wharf of the Odra River were defined. They were: very poor technical condition of the structure, lack of stabilizing anchors at the level of the wharf structure frames, and sudden fluctuations in water level in the river and their impact on the structure of the wharf. Moreover, from a static point of view, the embankment under the wharf was in an unstable equilibrium and at any time it could be damaged if additional horizontal forces were applied to it. Additionally, the possible impact of anchoring to the piers of the wharf of two river barges on wharf structure capacity was also analyzed.
\end{abstract}

\section{Description of the wharf structure}

The discussed wharf which, according to the archival documentation, was constructed around 1912 (Fig. 1), is situated on the left bank of the Odra's southern channel in Wroclaw. The wharf was designed and erected by the Schlesichse Betonbau Gesellshaft for the Schlesichse Dampfer Compagnie founded in 1887. In the following years, the company took on a special position in German inland shipping. It was a shipping and warehouse company and owned two shipyards. Its shipping was operated on the Oder, Elbe and the connecting channels.

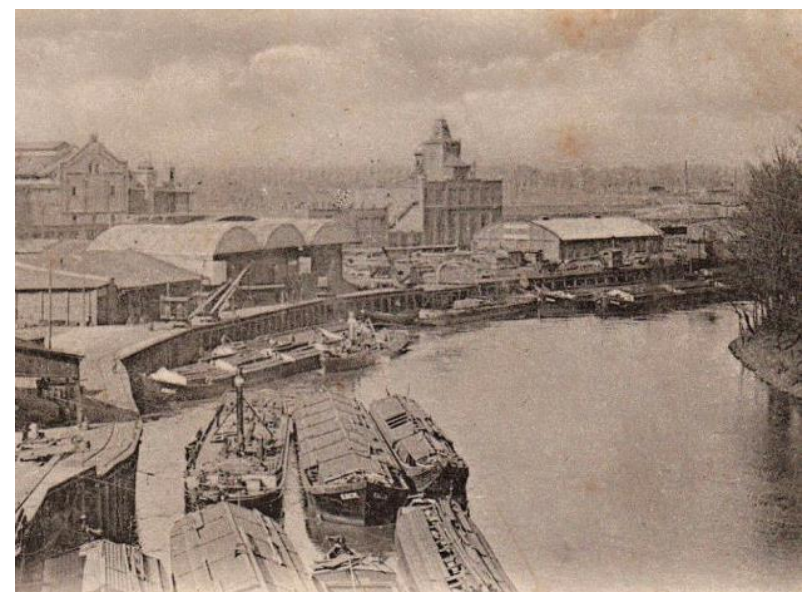

Fig. 1. Historical view of the wharf.

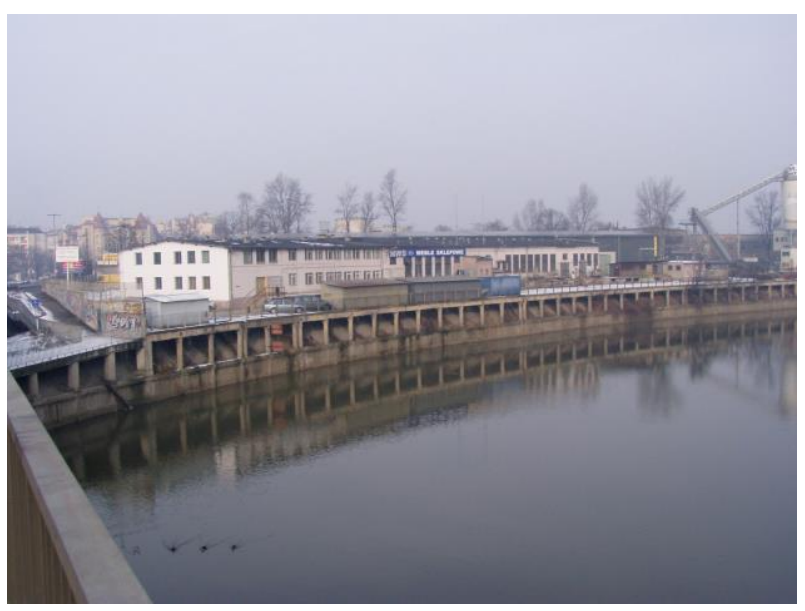

Fig. 2. General view of the wharf before failure.

In the past, the wharf served, among other, as a dockside quay for a brewery located nearby. In recent years, the wharf has been sporadically used for mooring barges. Even though the Odra embankments have been assessed [1] and renovated in recent years over a considerable length. the considered part was left without any technical intervention, repair or protection (Fig. 2).

\subsection{Analysis of the archival documentation}

The archival documentation consists of several drawings of the whole dockside quay with industrial buildings and

*Corresponding author: piotr.berkowski @pwr.edu.pl 


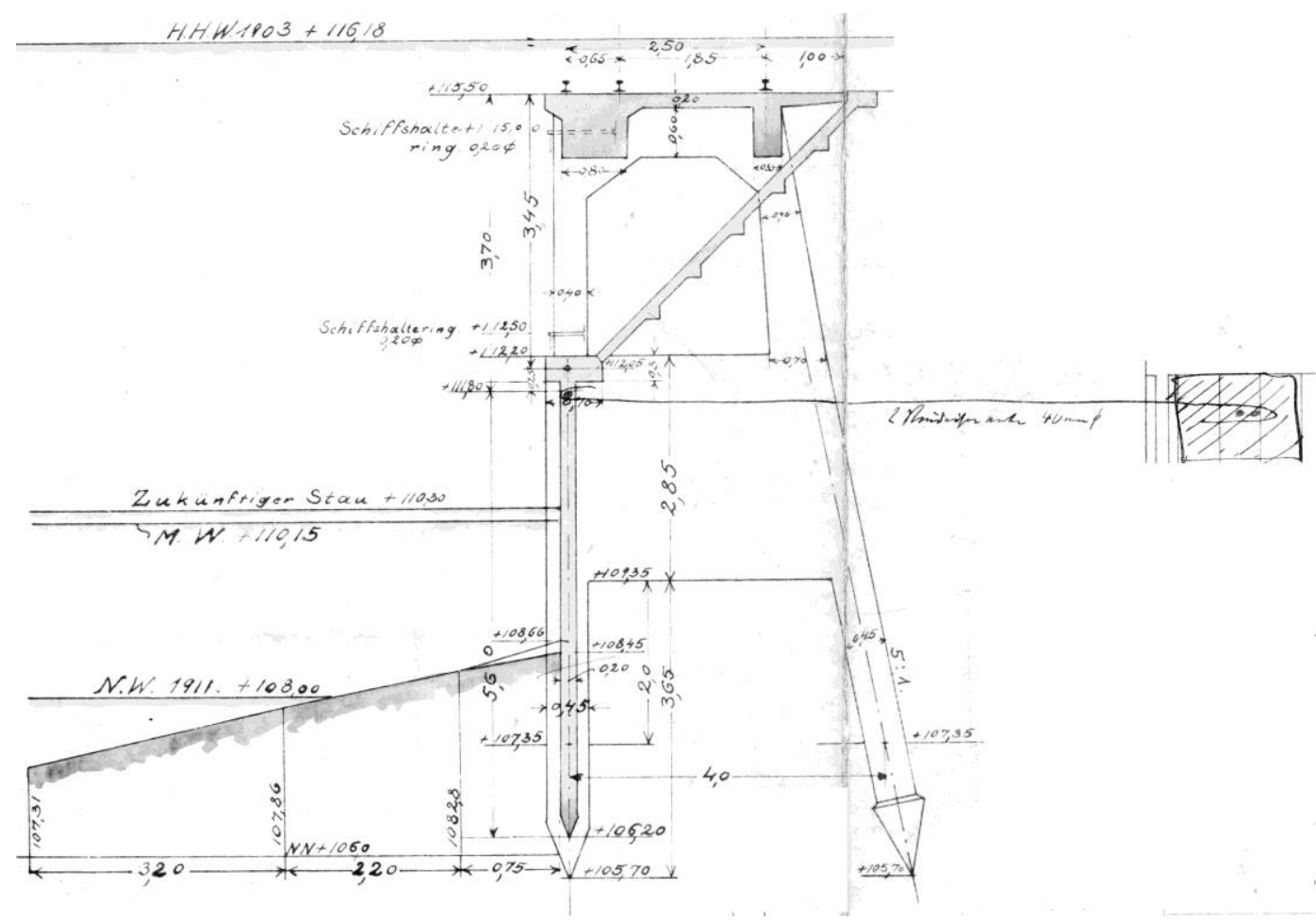

Fig. 3. Archival drawing of the wharf bearing structure.

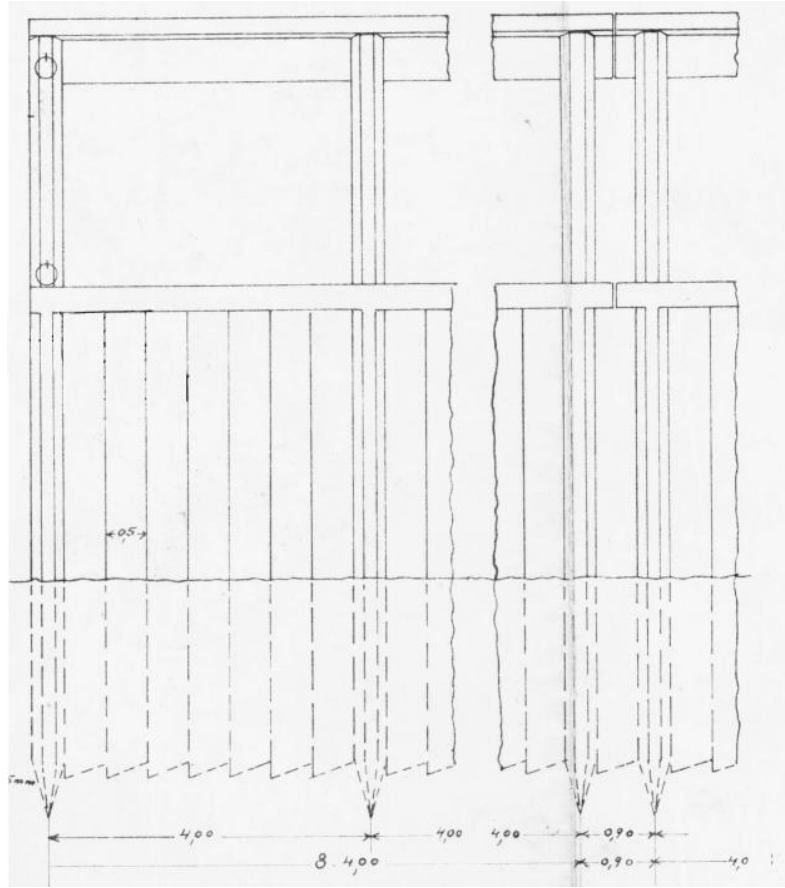

Fig. 4. View of the wharf with retaining wall.

selected structural drawings of the wharf frames and the retaining wall.

In the archival design, the total length of the wharf was $192.0 \mathrm{~m}$ and it was divided into six segments with a length of $32.0 \mathrm{~m}$ each. The structure of the wharf consists of the reinforced concrete " $\mathrm{H}$ " frames situated perpendicularly to the riverbed (Fig. 3). At ground level, the frames were connected by a reinforced concrete deck and two longitudinal beams located along the side of the river and the quay. The frames were also connected

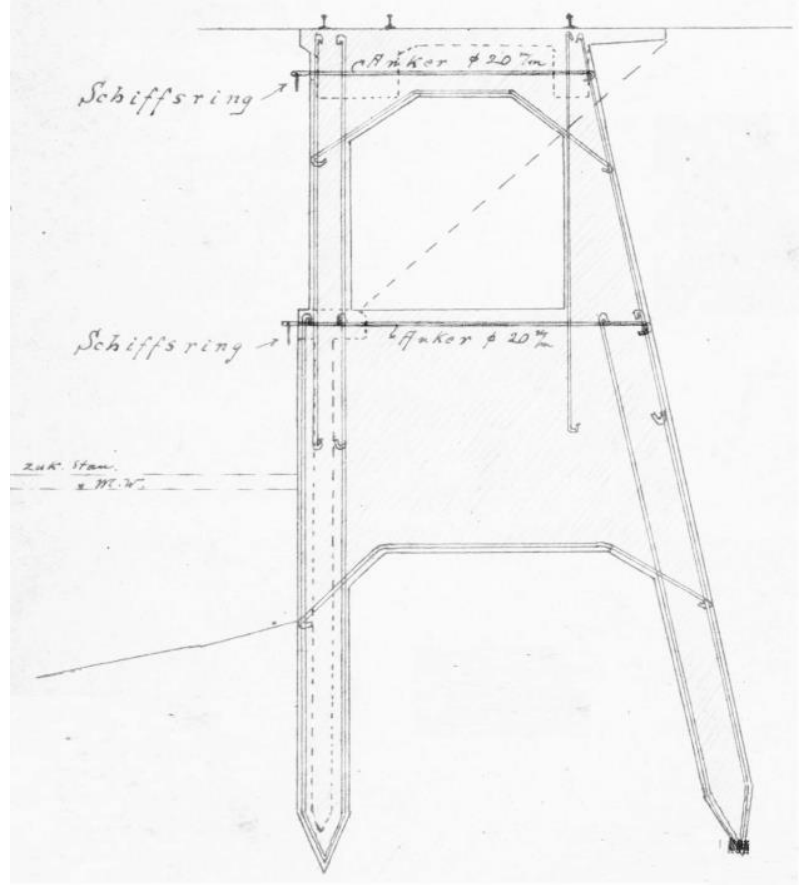

Fig. 5. Archival drawing of the wharf bearing structure rebar.

along the riverside by the concrete cap situated at the top of the retaining wall (Fig. 4) made of prefabricated panels and embedded in the bottom of the river. That wall constituted a direct strengthening and protection of the embankment (with an inclination of about $45^{\circ}$ ) against the influence of flowing river water. The total height of the bottom columns of the frame was $6.50 \mathrm{~m}$ and the upper part columns was about $3.30 \mathrm{~m}$ in height. The axial spacing of the lower pillars was $4.0 \mathrm{~m}$ and the width of the top deck was $3.80 \mathrm{~m}$ (Fig. 5). 


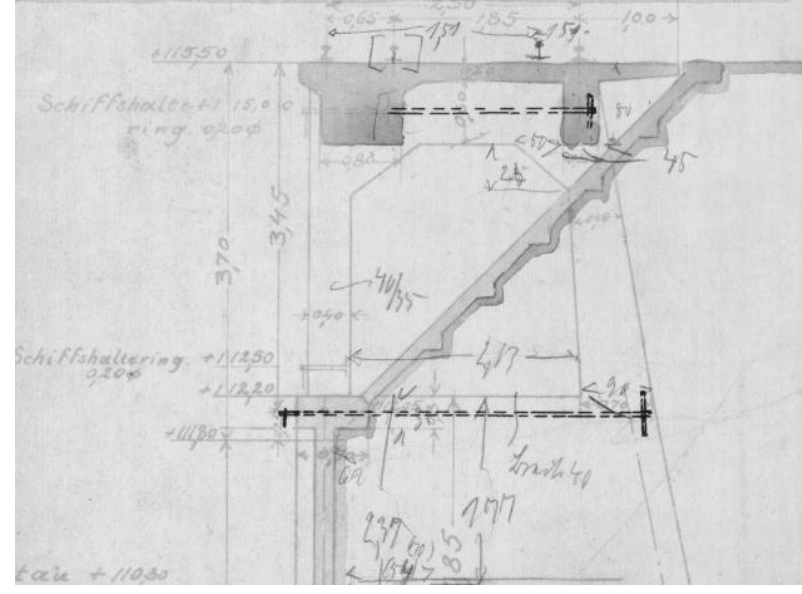

Fig. 6. Archival drawing of the frame with freehand sketches.

In two of the archival drawings it can be seen with the freehand sketches, that the reinforced concrete frames were to be additionally stabilized with steel anchors. In Fig. 3 it is designed by use of a $40 \mathrm{~mm}$ diameter rod at the level of the top of the cap covering the retaining walls (Fig. 3) and fixed in blocks located out of the embankment. The second proposal (Fig. 6) consists of inserting additional steel rods at two levels: between upper longitudinal beams and between columns at the level of cap over the retaining wall.

That fact will have some influence on the behavior of the wharf during failure.

\subsection{Description of the current structure of the wharf}

Currently, the whole wharf at this part of the river embankment is divided into 6 segments separated from each other by expansion joints). The first - no. I consists of 3 fields of $4.10 \mathrm{~m}$, no. II of 2 fields, and no. III, IV, V and VI have 10 fields each. The upper slab, based on the frames. girders and longitudinal beams, is approx. $3.3 \mathrm{~m}$ above the top of the lower cap constructed on the vertical retaining wall. Under the wharf board, a slope of about $45^{\circ}$ was made, connecting the retaining wall cap with the upper edge of the deck. The slope surface is strengthened by use of octagonal concrete blocks, while on the horizontal part of the embankment a stone pavement was made.

At present, the following elements of the reinforced concrete wharf structure can be distinguished (Fig. 7):

- A reinforced concrete retaining wall (sheet piling) made of prefabricated panels with a rectangular section $0.20 \times 0.50 \mathrm{~m}$ and $5.60 \mathrm{~m}$ long, combined with transverse frames and topped with a reinforced concrete cap $0.30 \mathrm{x} 0.70 \mathrm{~m}$;

- reinforced concrete transverse frames, consisting of the lower part $(6.50 \mathrm{~m}$ high) in the form of 2 piles with a cross section of $0.40 \times 0.45 \mathrm{~m}$, from which the pile introduced towards the wharf is an inclined pile, and the second one in the retaining wall line, is a vertical pile; these piles are connected with a reinforced concrete girder having height from 1.75 to $2.85 \mathrm{~m}$ below the upper level of the retaining wall, with a thickness of $0.40 \mathrm{~m}$; in the upper part $(3.30 \mathrm{~m}$ high), from the river side, the frame is made of a vertical pillar with an octagonal cross section of $0.35 \times 0.40 \mathrm{~m}$ and an oblique pillar with a width of $0.35 \mathrm{~m}$ and variable height from 0.50 to $0.90 \mathrm{~m}$; both pillars are connected at the top by a beam with a cross-section of $0.35 \times 0.55 \mathrm{~m}$ with slants;

- longitudinal beams, based on pillars of the upper girder of the supporting frames, with a cross section of $0.40 \times 0.55 \mathrm{~m}$; in the segment no. $\mathrm{V}$ beams from the river side have a cross-section of $0.30 \times 0.75 \mathrm{~m}$, and from the land side $-0.80 \times 0.75 \mathrm{~m}$;

- the upper slab (deck) of the wharf with a thickness of $0.20 \mathrm{~m}$ and width $3.80 \mathrm{~m}$, based on the longitudinal beams, situated along the river and with cantilever of $0.90 \mathrm{~m}$ along the line of the land.

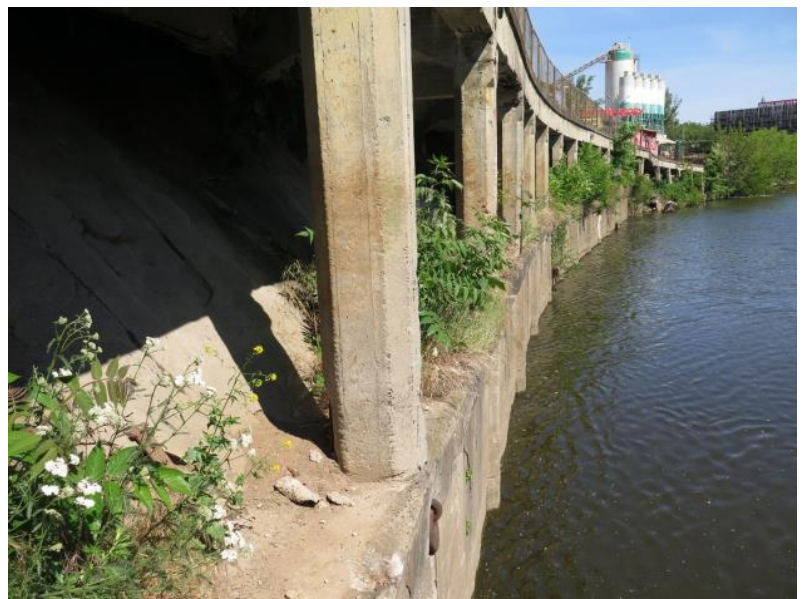

Fig. 7. Current view of the wharf structure.

\section{Assessment of the technical state of the destroyed wharf}

In May 2017 a structural and constructional failure of the reinforced concrete of the wharf occurred over a length of over $100 \mathrm{~m}$, mainly in the area of segments IV, V and VI. At those parts the embankment sloped down towards the river bed and its construction was locally completely destroyed (Fig. 8).

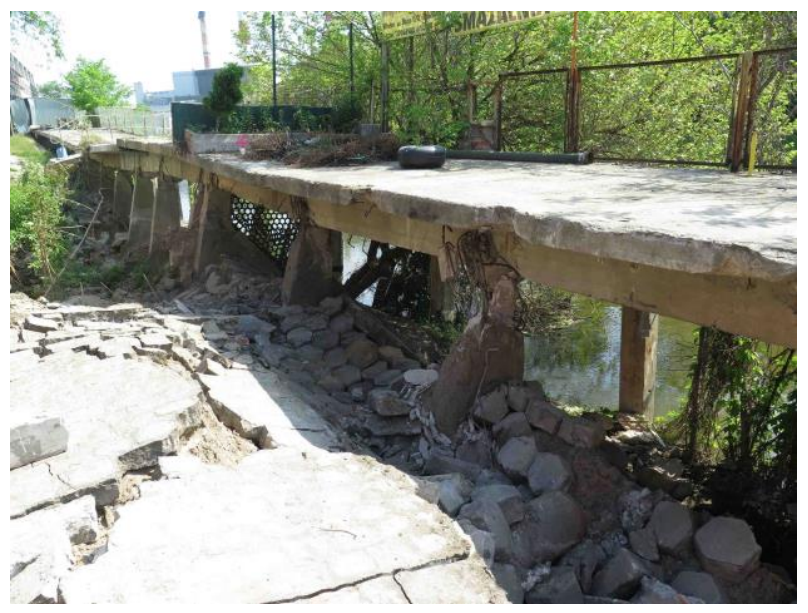

Fig. 8. General view of the destroyed embankment structure. 


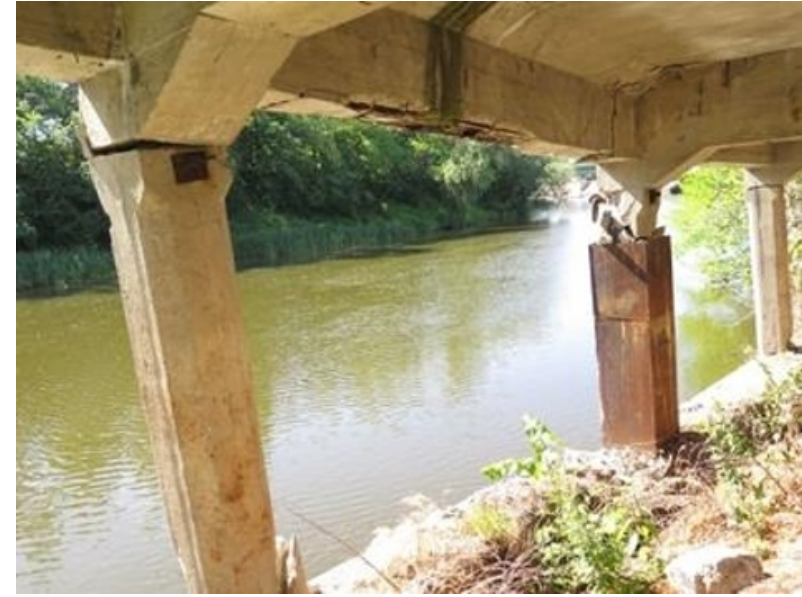

Fig. 9. View of the displaced wharf structure.

During the inspection made immediately after the failure it was also observed that the upper part of the wharf structure experienced about $15 \mathrm{~cm}$ displacement towards the river as well as along the shoreline, which was evident in the displacements experienced by the pillars and the reinforcement of columns and beams (Fig. 9).

At the time of the accident at the quay, two barges were moored in parallel to the embankment. Finally, it was found that the barges broke away from the wharf at one end and stood perpendicular to the current of the river channel, virtually blocking its total width for some time.

The assessment of the technical condition of the quay before the catastrophe was made on the basis of its postcatastrophic review, including some damaged and undamaged quays. A very bad, practically preemergency technical condition of the entire wharf structure was found. In many places there had been very large corrosion losses of concrete and reinforcement. At some parts practically the entire reinforcement cover had been completely destroyed and had lost its protective properties. The vast majority of reinforcement had corroded up to $30-40 \%$, some of the reinforcement was virtually completely destroyed. The total reinforcement loss was estimated to be at least $50 \%$.

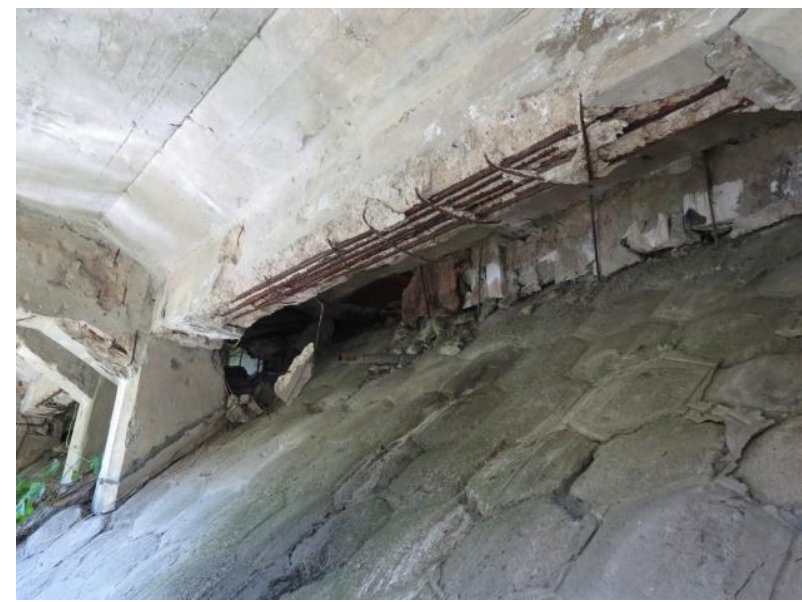

Fig. 10. Corrosion of concrete cover and reinforcement.

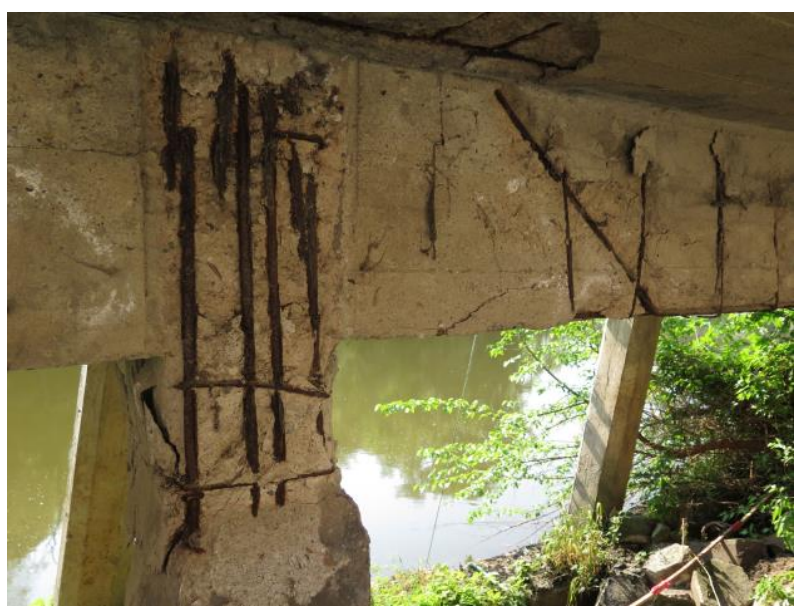

Fig. 11. Corrosion of concrete cover and reinforcement.

Already in the study from 2003 it had been indicated that the technical condition of the wharf was bad and further postponement of its repair might lead to a failure. Since then, no significant repairs had been carried out in the waterfront area and its technical condition had significantly deteriorated (Figs 10 \& 11).

In the procedure of assessing the technical condition of the driveway [2, 3, 4] the following material and structural examinations were made:

$>$ analysis of archival documentation;

$>$ geometrical and geodesic inventory of the structure;

$>$ damage inventory (including underwater filming);

$>$ drillings and geotechnical tests;

concrete and steel strength examination;

$>$ structural modelling and static calculations.

\subsection{Structural inventory}

The geometrical dimensions and reinforcement inventory of the upper part of the wharf structure were determined on the basis of archival documentation and authors' own measurements and on-site examination holes. While the bottom part was under water and covered with ground and was unavailable for measurement, so its inventory was made only based on archival documentation.

Verified with measurements, the geometrical dimensions of the wharf structure are described in the paragraph 1.2. In the case of dimensions and disposition of the reinforcement (smooth steel was used) it was conducted in places where the reinforcement was exposed as a result of the destruction of the quay structure. The following results were obtained and then used in static calculations:

$>$ top deck slab of the wharf:

- bottom $16 \mathrm{~mm}$ bars every $12 \mathrm{~cm}$, top $16 \mathrm{~mm}$ bars every $18 \mathrm{~cm}$, distribution rebar $10 \mathrm{~mm}$ every $30 \mathrm{~cm}$;

$>$ longitudinal beams:

- bottom 6 rods $18 \mathrm{~mm}$, with 3 slanted rods bent up to the top of the span; stirrups $6 \mathrm{~mm}$ every $17-30 \mathrm{~cm}$, in a denser spacing at supports;

$>$ transverse girders of the upper frames:

- bottom 7 rods $18 \mathrm{~mm}$; 
$>$ columns of the upper frame from the river side:

- 3 rods $18 \mathrm{~mm}$ distributed on each surface parallel to the river;

$>$ columns of the upper frame from the land side:

- 3 rods $18 \mathrm{~mm}$ from the water side, 4 rods 18 from the land side.

The reinforcement of the bottom frame columns was assumed according to the archival documentation as 10 rods $25 \mathrm{~mm}$ on the perimeter of the cross-section. The archival documentation also shows that reinforced concrete frames had been additionally stabilized with steel anchors with a diameter of $40 \mathrm{~mm}$ at the level of the top of the bottom girders connected the piles. After the failure of the wharf, a lot of extreme upper edges of those girders were exposed. In most cases, those anchors were not found. Only two anchors were found for the 2 frames in segment no. VI. They were rods with a diameter of $25 \mathrm{~mm}$ fixed to the reinforced concrete wall of one of the buildings located at the wharf. Those rods were completely corroded. In the calculations of the quay stability, it was assumed that originally stabilizing anchors with a diameter of $25 \mathrm{~mm}$ were present, but at the time of the failure they were not present or did not fulfill their function.

\subsection{Damage inventory}

During the failure a great part of the embankment sloped into the river. Geodesic measurements of its shape showed that it moved at the depth of about 3 to 4 meters. Simultaneously, also the reinforced concrete structure of the wharf moved towards the river causing massive cracking of the structural elements (Figs $12 \& 13$ ) along with pulling out the reinforcement at the connection points of the posts and the frame girders (Figs 14).

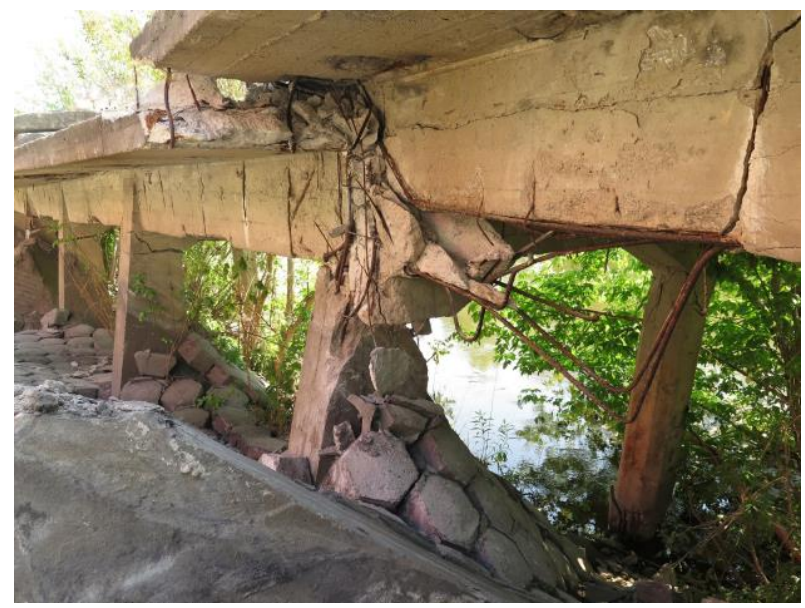

Fig. 12. Damaged wharf strucutre.

A few days after the disaster, the technical condition of the reinforced concrete piers in the segments V and VI was also checked below the then water table using a submarine camera. The level of the water table coincided with the top of the reinforced concrete cap. During the inspection, surface corrosion of the prefabricated concrete retaining wall panels was found, numerous defects of concrete on their surface and lack of tightness of contacts between them. However, taking into account the scale of displacements of the wall, in the upper part it has been preserved in the aforementioned review in a surprisingly good technical condition.

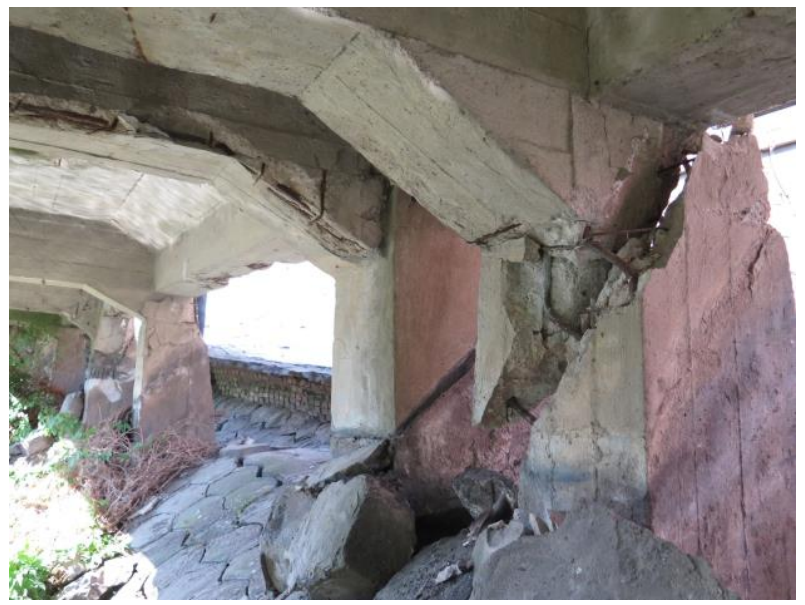

Fig. 13. Damaged wharf strucutre.

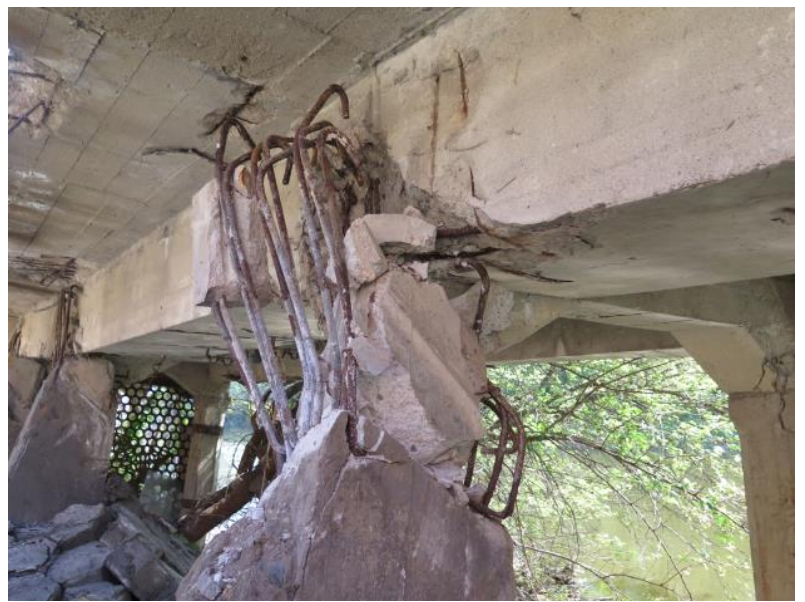

Fig. 14. Column rebars torn out of the frame..

\subsection{Geotechnical examination}

Due to covering of the disaster area with fragments of the destroyed construction, the test could only be carried out in two available places (Fig. 15). Soil research showed that under the $2 \mathrm{~m}$ thick layer of loose embankment there are fine compacted sands with a degree of density $I_{D}=0.46$ to 0.59 . Results of those tests were used to define embankment soil model for structural calculations.

During the geotechnical tests, the depth of the river bed was also measured in three places near the retaining wall. The bottom of the river bed (or the surface of the ingoing layers) was found at a level of approx. $4.5 \mathrm{~m}$ below the top of the cap connecting the panel wall. As the measurements were made after the landslide, the bottom of the river at the time of the failure could have been much lower. Therefore, it was at least $1.0 \mathrm{~m}$ below the level of the bottom assumed in the archival documentation, which meant a much shorter anchorage of the retaining wall in the bottom of the river. 


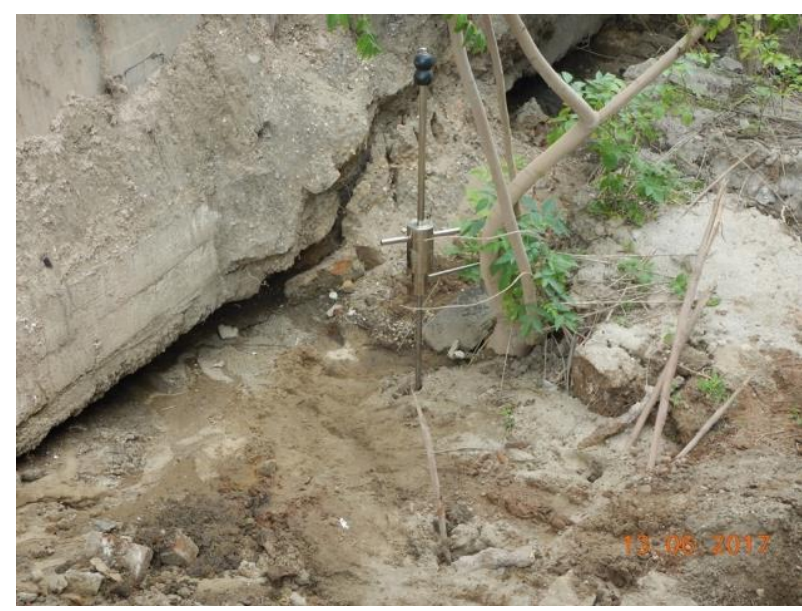

Fig. 15. Soil examination.

\subsection{Concrete and steel strength examination}

In order to determine the strength of reinforcing steel and concrete, several concrete blocks were removed and a number of reinforcing bars cut from the construction (Figs $16 \& 18$ ). Results of those tests (Figs $17 \& 19$ ) were used to define the wharf structure material models for structural calculations.

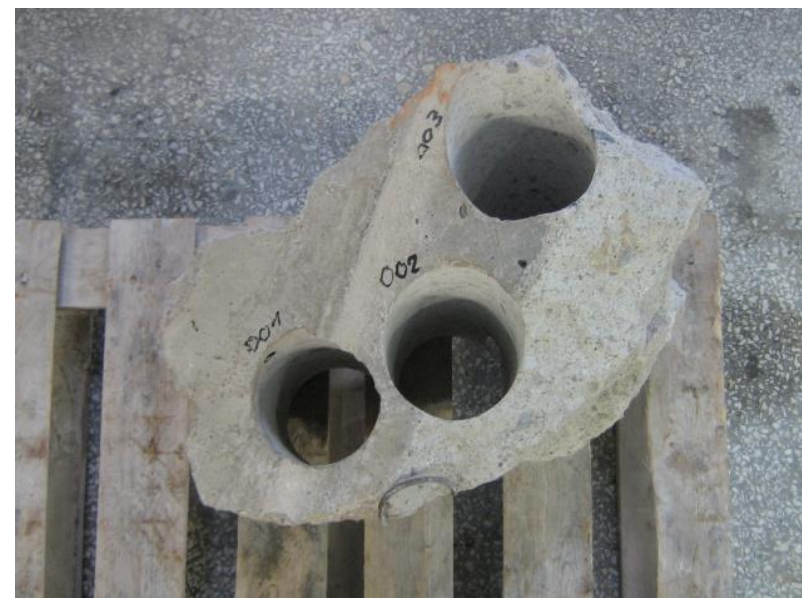

Fig. 16. Concrete probes.

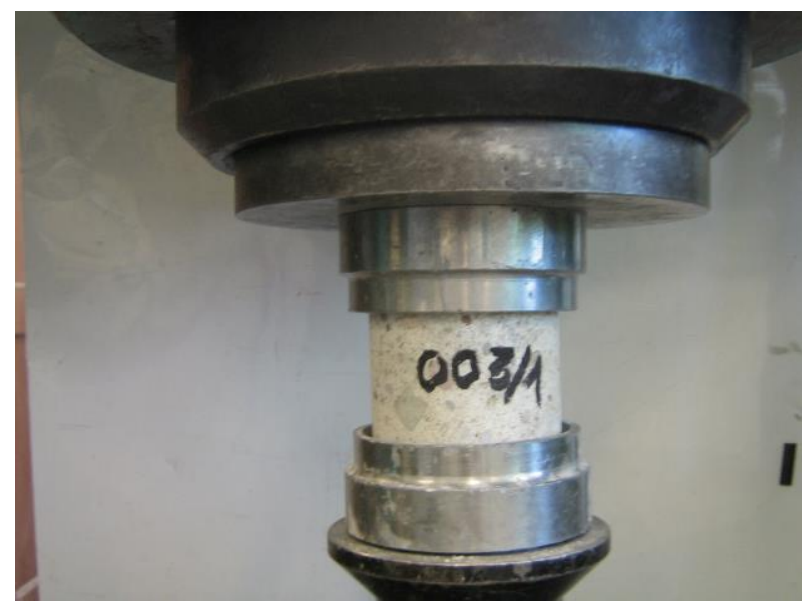

Fig. 17. Concrete testing.

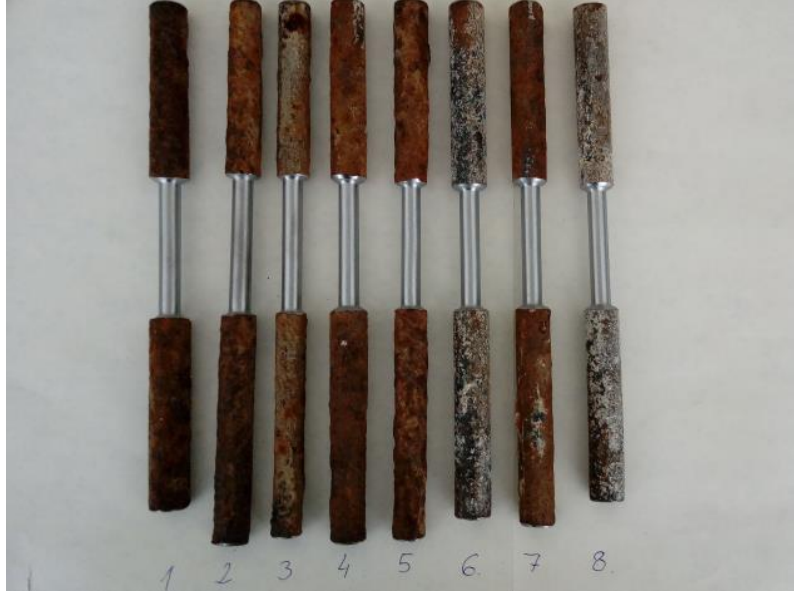

Fig. 18. Rebar probes.

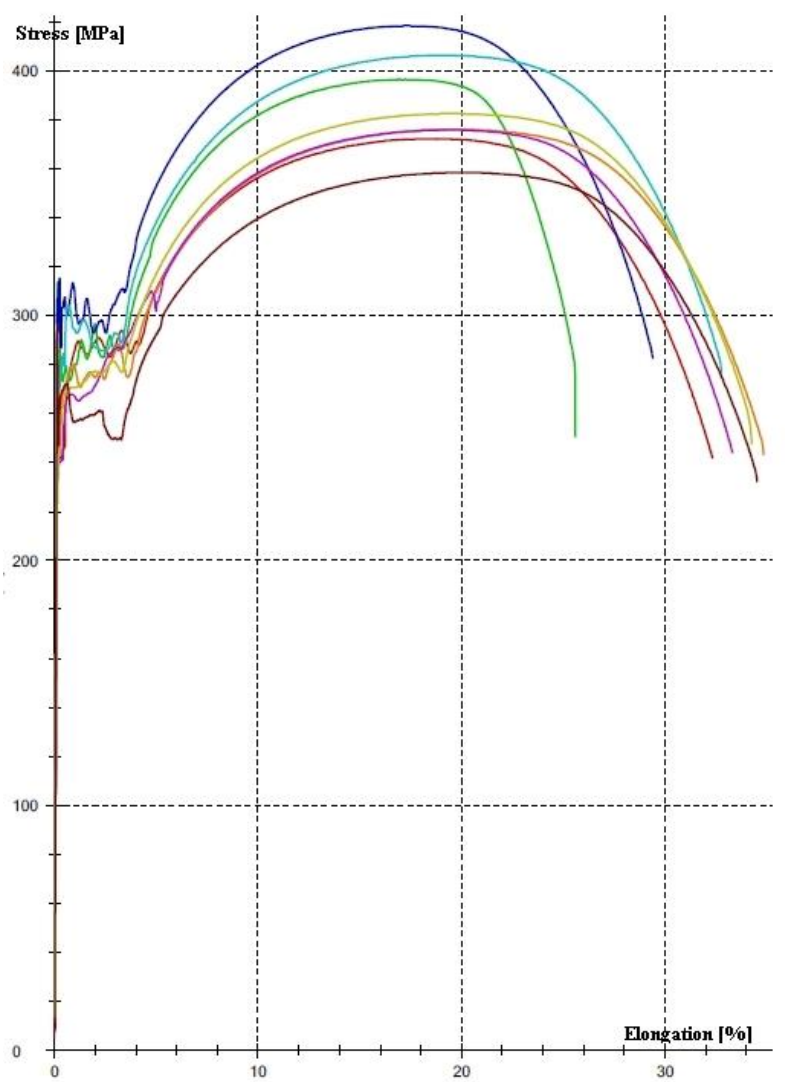

Fig. 19. Rebar test results.

A number of cylindrical samples were prepared and destroyed in accordance with the applicable standard (PN-EN 12390-3:2011) in order to determine the concrete class. The final test results and the strength value determined on the basis of a simple statistical analysis are presented below:

$\mathrm{f}_{\mathrm{csr}}=29.7 \mathrm{MPa}, \sigma=2.0 \mathrm{MPa}, \mathrm{f}_{\mathrm{G}}=29.7-1.64 \times 2.0=26.4$ $\mathrm{MPa}, \mathrm{f}_{\mathrm{ck}}=0.8 \times 26.4=21.1 \mathrm{MPa}, \mathrm{f}_{\mathrm{cd}}=21.1 / 1.5=14.0$ $\mathrm{MPa}$,

where: $\mathrm{f}_{\mathrm{csr}}$ - mean value of strength from $n$ samples; $\sigma$ standard deviation; $\mathrm{f}_{\mathrm{G}}-$ guaranteed compressive strength; $f_{c k}-$ characteristic compressive strength; $f_{c d}-$ compressive strength. 


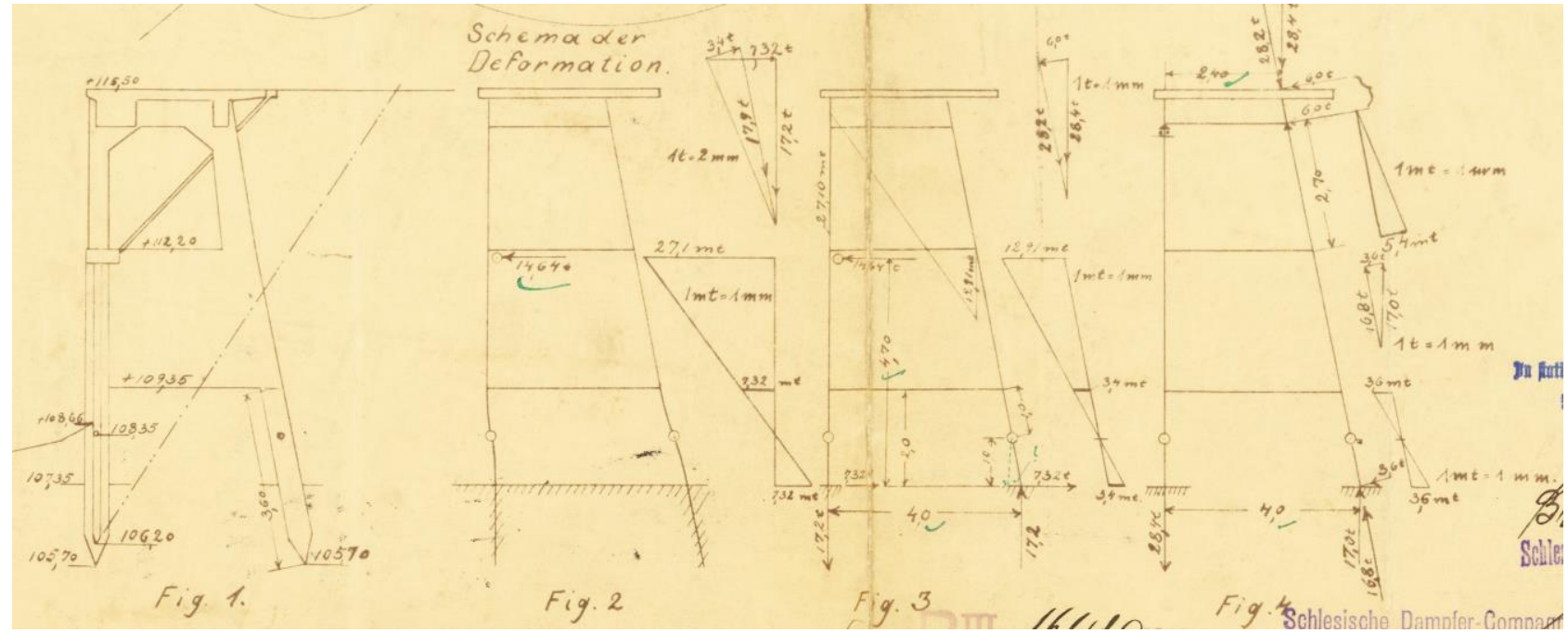

Fig. 20. Model of structural calculations for main frame assumed in the achival documentation.

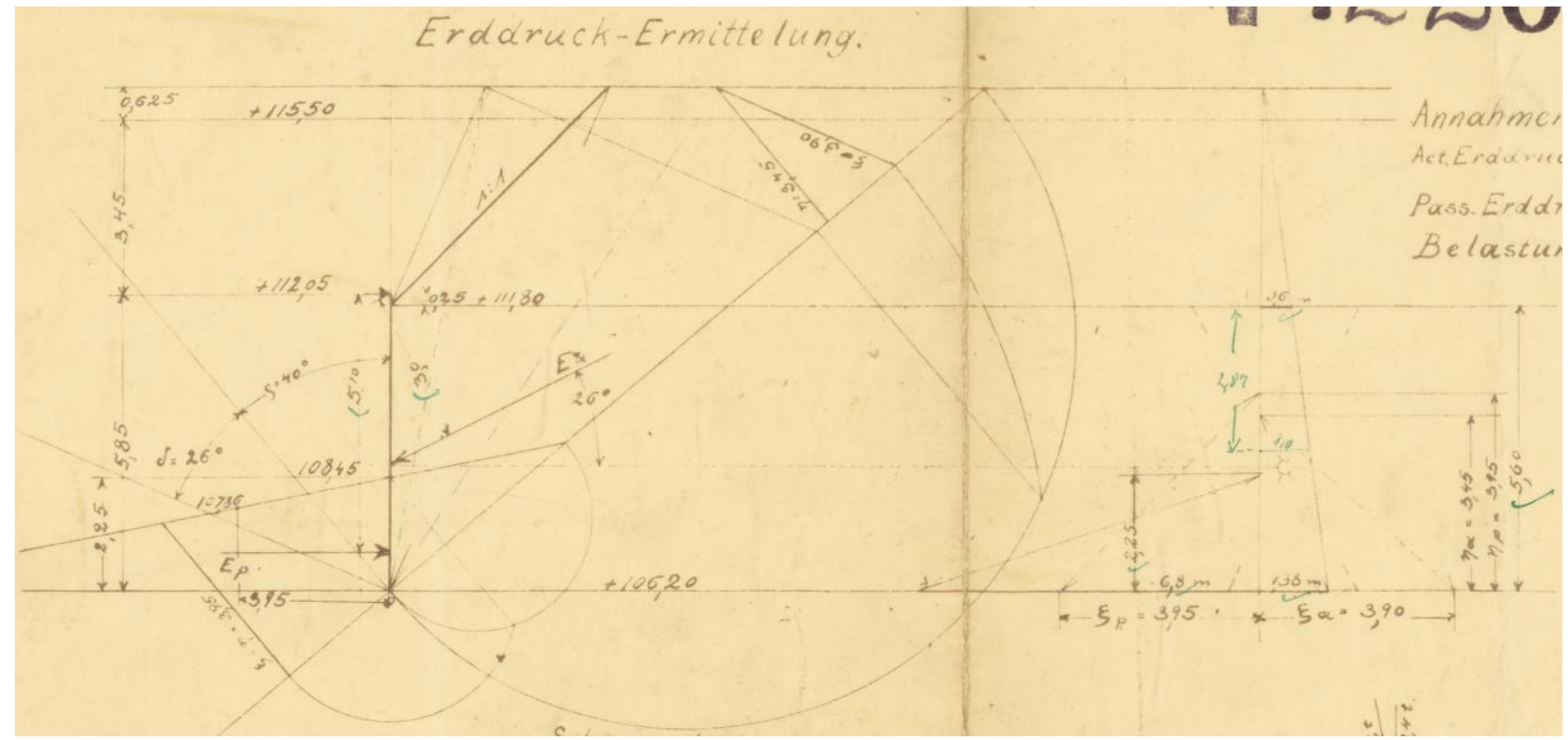

Fig. 21. Model of structural calculations assumed in the achival documentation for embankment stability.

Due to the very diverse state of concrete in the wharf structure, an average of class B15 (C12/C15) was assumed, although the results of the study indicates higher class.

To determine the strength of the reinforcing steel 8 samples of reinforcing bars were taken and broken in a strength machine. As a result of the tests, the following yield values were obtained:

$\mathrm{R}_{\mathrm{sr}}=386 \mathrm{MPa}, \sigma=20 \mathrm{MPa}, \mathrm{R}_{\mathrm{G}}=386-1.64 \times 20=353$

$\mathrm{MPa}, \mathrm{f}_{\mathrm{yk}}=0.8 \times 353=282 \mathrm{MPa}, \mathrm{f}_{\mathrm{yd}}=282 / 1.15=245$ $\mathrm{MPa}$,

where: $\mathrm{R}_{\text {sr }}$ - mean value of strength from $n$ samples; $\sigma-$ standard deviation; $\mathrm{R}_{\mathrm{G}}$ - guaranteed tensile strength; $\mathrm{f}_{\mathrm{yk}}$ - characteristic tensile strength; $f_{y d}-$ tensile strength.

The yield limit $f_{y d}=210 \mathrm{MPa}$ for steel was taken for the structural calculations.

\subsection{Structural modelling and calculations}

In the archival documentation, some drawings with graphical calculations for the main frame design (Fig. 20) and for verification of embankment stability (Fig. 21) were found.

In the calculations related to the assessment of the technical condition of the wharf structure, in order to determine the causes of the catastrophe, simplified static and strength calculations of the upper part of the wharf structure were performed as well as verification of its stability for various calculation situations.

The results of calculations of the bearing capacity of the frame elements allowed us to conclude that even with the assumption of $50 \%$ reinforcement loss, the wharf structure should have been able to transfer service 
vertical loads of $5 \mathrm{kN} / \mathrm{m}^{2}$, and the forces generated from the barges should not cause direct damage to the wharf structure.

The scope of analyzes regarding the stability test of the quay included 2D numerical simulations in a plane deformation state for five wharf calculation and work models:

$>$ state immediately after its construction;

$>$ state after lowering the bottom of the river;

$>$ state after loosening the ground behind the piling wall;

$>$ state at the moment of the loss of load-bearing capacity of the anchor rods;

$>$ state after applying external load from barges mooring forces.

Based on the calculations carried out, which also included the history of the construction of the wharf structure, it was found that assuming a structure without anchoring or with severe corrosion of the anchors (insufficient load capacity), the embankment was practically in a state of unstable equilibrium and could have been damaged due to the existence of some additional factor. The calculations of the wharf were conducted with the assumptions which were generally favorable for its stability, namely the adoption of high water level and the lowering of the river bed only about $1 \mathrm{~m}$ below archival design. In the considered case, the additional factor that could have caused the waterfront failure might be forces from mooring barges and greater than the assumed depth of the river. Assuming loading the wharf with the forces from the barges (when the barges break off at one end from the wharf), the model was unstable with the possibility of large displacements of the structure.

\section{Final remarks}

Basing on the performed assessment of the damaged river reinforced concrete wharf main reasons of its failure were defined. The most important factor was a very poor technical condition of the structure due to more than 100 year of service without proper conservation and repair. Additionally, from a static point of view, the embankment under the wharf was in an unstable equilibrium and at any time it could be damaged if additional horizontal forces or phenomena related to the flow of the river appeared. The analyzes carried out showed that the factors that could initiate the destruction process of the wharf included: lack or destruction of the stabilizing anchors, sudden fluctuations in river water level [5] and horizontal forces originating from barges moored to the piers of the quay bearing frames. Coupling all of the above factors caused the destruction of the part of the wharf and the necessity of its reconstruction.

Currently, the undestroyed part of the wharf has been protected using a sheet pile retaining wall with Larsen profiles (Fig. 22), while the destroyed part is going to be completely rebuilt.

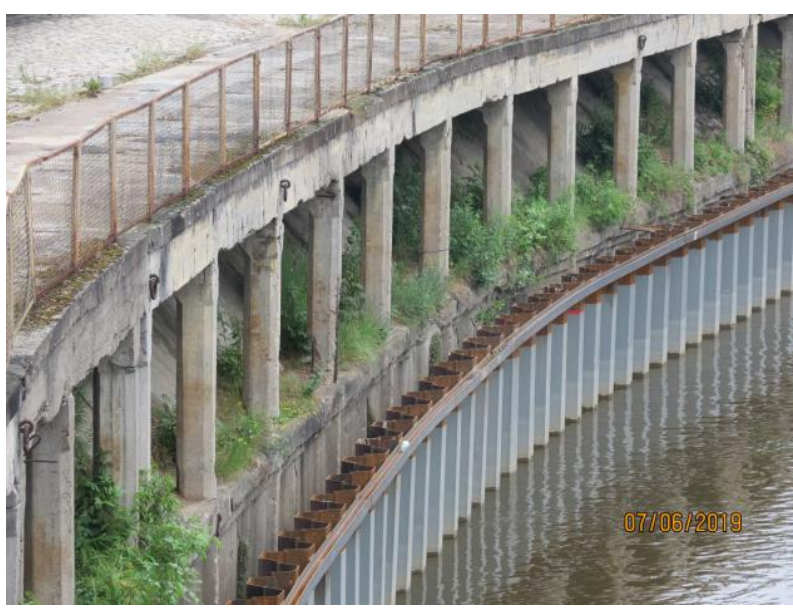

Fig. 22. Sheet piling retaining wall

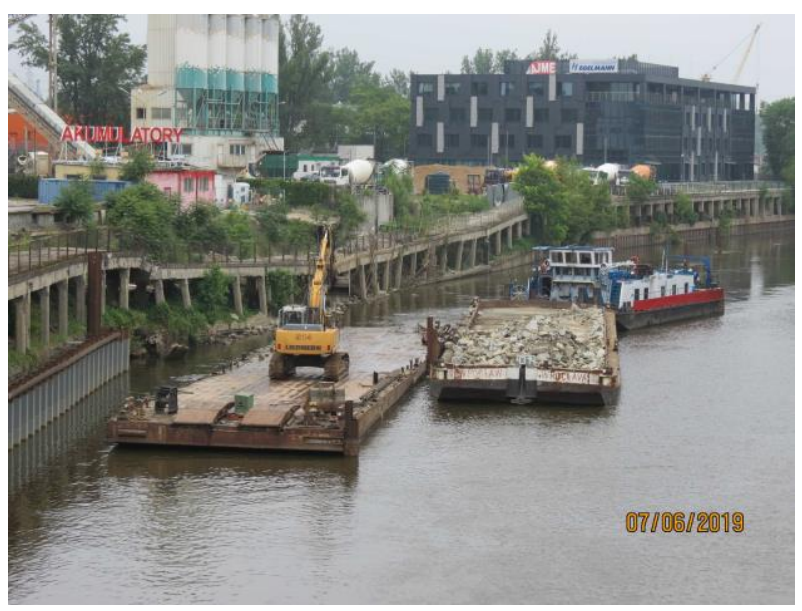

Fig. 23. Reconstruction works on the destroyed wharf.

\section{References}

1. J. Bień, T. Kamiński, P. Rawa, Emergency conditions of masonry embankments of the Odra river in Wroctaw, Proc. of 27th Scientific and Technical Conference Construction Failures, Międzydroje 2015 (in Polish)

2. Ł. Dorbiec, R. Jasiński, A. Piekarczyk, Diagnostics of Reinforced Concrete Structures. Methodology, field tests, laboratory tests of concrete and steel (PWN, Warsaw, 2010) (in Polish)

3. A. Zybura, M. Jaśniok, T. Jaśniok, Diagnostics of Reinforced Concrete Structures. Tests of reinforcement corrosion and protective properties of concrete (PWN, Warsaw, 2011) (in Polish)

4. M. Raupach, T. Büttner, Concrete Repair to EN 1504. Diagnosis, Design, Principles and Practice (CRC Press, Boca Raton, 2014)

5. K. Parylak, K. Witek, Complexity of conditions of the causes of the disaster of the Odra reloading wharf, Acta Sci. Pol. Architectura, 17 (3) 2018 